OPEN ACCESS

Edited by: Belén Feriche,

Universidad de Granada, Spain

Reviewed by: Igor Štirn,

University of Ljubliana, Slovenia Jose Lopez Chicharro, Complutense University of Madrid,

Spain

Enrique G. Artero,

University of Almería, Spain

*Correspondence:

Billy Sperlich

billy.sperlich@uni-wuerzburg.de

Specialty section: This article was submitted to

Exercise Physiology, a section of the journal

Frontiers in Physiology

Received: 15 November 2017 Accepted: 04 April 2018

Published: 09 May 2018

Citation:

Sperlich B, Hahn L-S, Edel A, Behr T, Helmprobst J, Leppich R,

Wallmann-Sperlich $B$ and

Holmberg H-C (2018) A 4-Week Intervention Involving Mobile-Based

Daily 6-Minute Micro-Sessions of Functional High-Intensity Circuit

Training Improves Strength

and Quality of Life, but Not Cardio-Respiratory Fitness of Young

Untrained Adults.

Front. Physiol. 9:423.

doi: 10.3389/fphys.2018.00423

\section{A 4-Week Intervention Involving Mobile-Based Daily 6-Minute Micro-Sessions of Functional High-Intensity Circuit Training Improves Strength and Quality of Life, but Not Cardio-Respiratory Fitness of Young Untrained Adults}

\author{
Billy Sperlich ${ }^{1 *}$, Lea-Sofie Hahn ${ }^{1}$, Antonia Edel ${ }^{1}$, Tino Behr ${ }^{1}$, Julian Helmprobst ${ }^{1}$, \\ Robert Leppich ${ }^{1}$, Birgit Wallmann-Sperlich ${ }^{2}$ and Hans-Christer Holmberg ${ }^{3,4,5}$ \\ ${ }^{1}$ Integrative and Experimental Exercise Science and Training, Institute for Sport Sciences, University of Würzburg, Würzburg, \\ Germany, ${ }^{2}$ Institute for Sport Sciences, University of Würzburg, Würzburg, Germany, ${ }^{3}$ The Swedish Winter Sports Research \\ Centre, Mid Sweden University, Östersund, Sweden, ${ }^{4}$ School of Kinesiology, The University of British Columbia, Vancouver, \\ BC, Canada, ${ }^{5}$ School of Sport Sciences, UiT The Arctic University of Norway, Tromso, Norway
}

The present study was designed to assess the psycho-physiological responses of physically untrained individuals to mobile-based multi-stimulating, circuit-like, multiple-

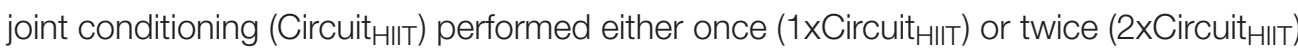
daily for 4 weeks. In this single-center, two-arm randomized, controlled study, 24 men and women (age: $25 \pm 5$ years) first received no training instructions for 4 weeks and then performed 4 weeks of either 1 xCircuit $_{\text {HIT }}$ or 2 xCircuit $_{H}$ IIT $(5$ men and 7 women in each group) daily. The $1 \times$ Circuit $_{H I T}$ and 2 Xircuit $_{H I T}$ participants carried out 90.7 and $85.7 \%$ of all planned training sessions, respectively, with average heart rates during the 6-min sessions of 74.3 and $70.8 \%$ of maximal heart rate. Body, fat and fat-free mass, and metabolic rate at rest did not differ between the groups or between time-points of measurement. Heart rate while running at $6 \mathrm{~km} \cdot \mathrm{h}^{-1}$ declined after the intervention in both groups. Submaximal and peak oxygen uptake, the respiratory exchange ratio and heart rate recovery were not altered by either intervention. The maximal numbers of push-ups, leg-levers, burpees, $45^{\circ}$-one-legged squats and 30 -s skipping, as well as

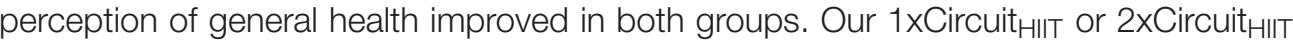
interventions improved certain parameters of functional strength and certain dimensions of quality of life in young untrained individuals. However, they were not sufficient to enhance cardio-respiratory fitness, in particular peak oxygen uptake.

Keywords: aerobic fitness, body composition, functional training, mHealth, power training, V800, wearable, Webbased apps 


\section{INTRODUCTION}

Low levels of cardiorespiratory fitness (CRF) and physical activity (PA) are two major independent risk factors for both cardiovascular disease (CVD) and all-cause mortality (Blair et al., 1989; DeFina et al., 2015). Programs designed to improve cardiovascular, metabolic and psychological health involving repeated short-to-long bouts of high-intensity exercise with intervals of recovery (referred to as high-intensity interval training or HIIT) have begun to replace those based on lowintensity high-volume exercise (Kessler et al., 2012; Elliott et al., 2014; Little and Francois, 2014; Gielen et al., 2015; Schmitt et al., 2016). In addition to encompassing an unlimited number of protocols with different work-to-rest ratios, orders of loading and distributions of training intensity, HIIT requires less time and perceived lack of time appears to be a major reason for not exercising (Godin et al., 1994).

Accumulating evidence indicates that low-volume HIIT (e.g., 4-6 30-s cycle sprints separated by $\sim 4$ min of recovery or 10 60-s work bouts at a constant intensity that elicits $\sim 90 \%$ of maximal heart rate, separated by $60 \mathrm{~s}$ of recovery) induces physiological remodeling in several ways that improve metabolic control in skeletal muscle, as well as cardiovascular function (Gibala et al., 2012). Such metabolic improvement is beneficial to numerous individuals, including previously sedentary, overweight individuals in whom insulin sensitivity can be improved by this type of exercise (Whyte et al., 2010).

As has shown to be the case for traditional endurancebased HIIT, the relatively novel functional training/fitness involving multi-stimulating, circuit-like, multiple-joint, highintensity exercise (Circuit HIIT) improves body composition, as well as cardiovascular and functional fitness and certain aspects of quality of life (Sperlich et al., 2017). Improved CRF (e.g., maximal oxygen uptake) and muscular strength are associated with improved dimensions of health (Nikander et al., 2010; Thomas et al., 2017) and fewer premature deaths (Bouchard et al., 2015). However, although time-saving bouts of sprint-based HIIT enhance certain dimensions of health, this type of training is extremely demanding; may not be safe, tolerable or appealing for certain individuals (Gibala et al., 2012); and may not improve whole-body strength.

Mobile web-based technology is growing rapidly and now offers more than 100,000 applications (Modave et al., 2015) designed to improve various aspects of health and physical fitness (Sama et al., 2014; Modave et al., 2015). Digital technology may effectively reduce the length of contact time between individuals seeking care and health or exercise professionals (Atkinson and Gold, 2002) and thereby the costs involved. Numerous mobile apps presently available, especially in iTunes and Google Play,

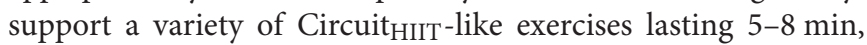
micro-sessions which may, if performed for approximately 75 min each week (i.e., approximately twice a day), be in line with current recommendations for improving and maintaining physical fitness and health (Garber et al., 2011).

Improvement in neuromuscular function through aerobic exercise is associated with other health benefits, including reduced lower-back pain (Cortell-Tormo et al., 2018), enhanced bone density (Petersen et al., 2017), better body composition (Cholewa et al., 2017) and more favorable psychological perception (e.g., self-satisfaction, self-esteem and body image) (Sothern et al., 1999). In this context, short-term (i.e., 4-week) resistance training has been proven to improve the one-repetition concentric strength of sedentary, healthy men by 19\% (Raue et al., 2005), as well as to elevate the maximal isometric torque of both healthy men and women (Mayhew et al., 1995).

Micro-sessions of Circuit ${ }_{\text {HIT }}$ may offer one approach to circumventing lack of time as a reason for not exercising (Godin et al., 1994). However, a recent systematic review highlighted the fact that physical activity promoted by smart phones leads to heterogeneous outcomes (Bort-Roig et al., 2014) and does not apply evidence-based guidelines to aerobic and resistance training (Knight et al., 2015). Thus, although promoted extensively online, surprisingly little scientific evaluation of the effect of web-based interventions, including Circuit $_{\text {HIIT, }}$ on cardiorespiratory and metabolic functions, body composition, functional strength and quality of life of untrained individuals is presently available.

Therefore, we have compared here the psycho-physiological responses of physically untrained individuals to a webbased multi-stimulating, circuit-like, multiple-joint conditioning program (Circuit $\left.{ }_{\text {HIIT }}\right)$ performed either once $\left(1 \mathrm{xCircuit}_{\mathrm{HIIT}}\right)$ or twice (2xCircuit HIIT $_{\text {T }}$ ) daily for 4 weeks.

\section{MATERIALS AND METHODS}

\section{Participants}

For this single-center, two-arm randomized, controlled study, 24 men and women (major baseline characteristics are summarized in Table 1) were recruited via social media and bulletins. They were assigned randomly to perform a 6-min web-based microsession of functional high-intensity circuit training, individually designed on the basis of their peak oxygen uptake at baseline, either once $\left(1 \mathrm{xCircuit}{ }_{\mathrm{HIT}}\right)$ or twice $\left(2 \mathrm{xCircuit}_{\mathrm{HIT}}\right)$ ( 5 men and 7 women in each case) daily for 4 weeks. $T$-test analysis of $\mathrm{VO}_{2 \text { peak }}$ prior to the intervention demonstrated no difference in this respect between the two groups ( $p=0.75 ; T=0.32$ ).

All were informed in detail about the design of the study, including the potential risks and benefits, before providing their written consent to participate. The inclusion criteria were an age of 18-40 years; lack of any frequent participation in endurance or strength exercise programs for at least 6 months prior to the study; no daily intake of medication; and for inclusion in the analysis, completion of at least $80 \%$ of the training sessions.

All procedures were conducted in accordance with the Declaration of Helsinki and the experimental protocol was approved by the ethical review board of the Sport Science Institute of the University of Würzburg.

\section{Overall Study Design}

Two to 3 days prior to $\left(\mathrm{T}_{0}\right)$ and 2 days after the 4 -week baseline period $\left(\mathrm{T}_{1}\right)$, as well as two to 3 days following the 4-week Circuit ${ }_{\text {HIT }}$ intervention $\left(\mathrm{T}_{2}\right)$, all underwent assessment of body composition, a treadmill ramp test designed to assess 
TABLE 1 | Anthropometric characteristics of and peak oxygen uptake by our participants at baseline.

\begin{tabular}{|c|c|c|c|c|c|}
\hline Circuit $_{\text {HIIT }}$ group & Sex & Height [cm] & Mass [kg] & Body mass index $\left[\mathrm{kg} \cdot \mathrm{m}^{-2}\right]$ & $\mathrm{VO}_{2 \max }\left[\mathrm{ml} \cdot \mathrm{min}^{-\mathrm{z} 1} \cdot \mathrm{kg}^{-1}\right]$ \\
\hline \multirow[t]{3}{*}{$1 x$} & Men & $190.8 \pm 6.3$ & $85.2 \pm 2.1$ & $23.5 \pm 1.5$ & $45.7 \pm 1.1$ \\
\hline & Women & $169.6 \pm 4.1$ & $67.0 \pm 7.0$ & $23.3 \pm 2.2$ & $38.5 \pm 5.1$ \\
\hline & Combined & $176.7 \pm 11.2$ & $73.1 \pm 10.6$ & $23.3 \pm 1.9$ & $40.9 \pm 5.5$ \\
\hline \multirow[t]{3}{*}{$2 x$} & Men & $180.0 \pm 8.1$ & $83.2 \pm 13.7$ & $25.6 \pm 3.5$ & $40.4 \pm 5.1$ \\
\hline & Women & $167.86 \pm 3.7$ & $62.6 \pm 9.6$ & $22.2 \pm 3.1$ & $39.8 \pm 8.5$ \\
\hline & Combined & $172.92 \pm 8.4$ & $71.2 \pm 15.2$ & $23.6 \pm 3.6$ & $40.1 \pm 7.0$ \\
\hline
\end{tabular}

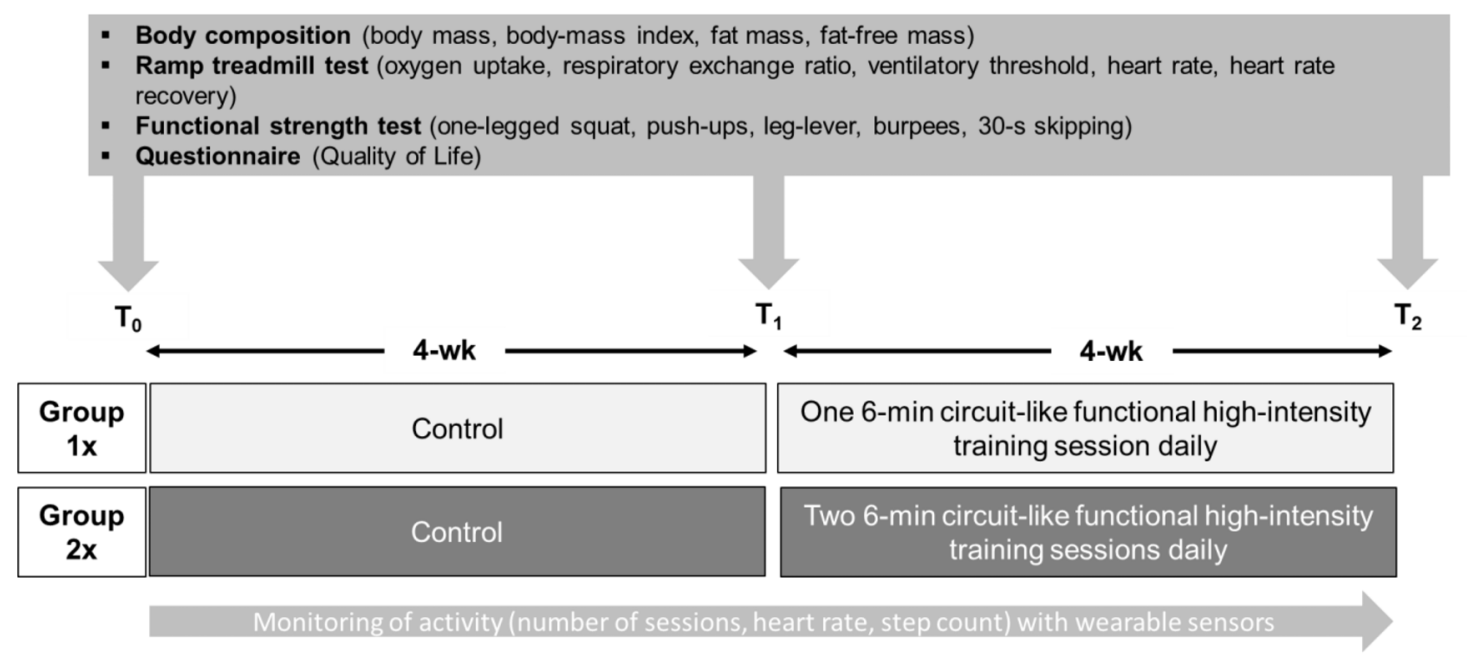

FIGURE 1 | The study design, including testing prior to $\left(T_{0}\right)$ and after $\left(T_{1}\right)$ the baseline period and following the intervention $\left(T_{2}\right)$.

cardiorespiratory and metabolic variables, and numerous tests of functional movement and strength, as well as filling in a questionnaire concerning quality of life (Figure 1).

\section{The Interventions}

Each of the 4 weeks of intervention involved a different

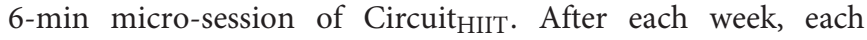
participant received a web-based video (designed for use either on a desktop computer or smartphone/tablet) of an instructor carrying out functional Circuit HIT $_{\text {Tovements [for }}$ details, see (www.sportsandscience.de, 2017a,b,c,d)] and were instructed to follow these movements with high-intensity, with monitoring of this intensity by heart rate. The $2 \mathrm{xCircuit}_{\mathrm{HIT}}$ group was instructed to recover for 2-3 h between the two sessions on the same day. All sessions and other freetime activities were monitored by a multi-sensor device worn on the wrist (Polar V800, Polar Electro Oy, Kempele, Finland).

\section{Anthropometric Data and Body Composition}

Height while standing barefoot was measured with a folding yardstick. Body, fat and fat-free mass, as well as metabolic rate at rest were assessed with a four-electrode bio-impedance scale (Model 1609N; Tanita Corp., Tokyo, Japan) and the bodymass-index (BMI; in $\mathrm{kg} \cdot \mathrm{m}^{-2}$ ) then calculated. Since dehydration may affect such bio-impedance analysis, all participants were instructed to drink $500 \mathrm{~mL}$ of water $1 \mathrm{~h}$ before these measurements.

\section{The Treadmill Test}

After running at $6 \mathrm{~km} \cdot \mathrm{h}^{-1}$ for $5 \mathrm{~min}$ on a treadmill (Mercury, h/p/Cosmos Sports \& Medical GmbH, Nußdorf, Germany), submaximal heart rate, oxygen uptake and the respiratory exchange ratio were all evaluated. Thereafter, for determination of the peak values of these same parameters, the speed was increased by $1 \mathrm{~km} \cdot \mathrm{h}^{-1}$ each minute until exhaustion. As recommended earlier (Poole and Jones, 2017), a ramp test involving constant work at approximately $110 \% \mathrm{VO}_{2 \text { peak }}$ was performed shortly thereafter for validation and the higher of the two values obtained considered to be $\mathrm{VO}_{2 \text { peak }}$. Heart rate recovery $\left(\mathrm{HR}_{\text {recovery }}\right)$ was defined as the reduction in heart rate while standing still during the first $60 \mathrm{~s}$ after termination of the ramp test.

Throughout the testing, oxygen uptake, the respiratory exchange ratio and heart rate were monitored with an open circuit breath-by-breath gas and volume analyzer (Metamax 3B, Cortex Biophysik GmbH, Leipzig, Germany), employing standard algorithms to compensate for the delay between oxygen consumption and generation of the signal. All respiratory data and heart rates were averaged over 30-s intervals. The oxygen uptake at $6 \mathrm{~km} \cdot \mathrm{h}^{-1}$ was considered to be an indicator of running economy, as described elsewhere (Barnes and Kilding, 2015). 
Post-exercise heart rate recovery is considered to be a marker for general hemodynamic adjustments and this 60-s recovery is correlated to changes in training status (Daanen et al., 2012).

\section{Functional Strength and 30-s Skipping}

To test functional strength, all participants were asked to perform as many push-ups, leg-levers, burpees and $45^{\circ}$-one-legged squats in $1 \mathrm{~min}$ as they could (separated by $3 \mathrm{~min}$ of recovery). All of this functional testing was adopted from a previous study (Sperlich et al., 2017). Repeated testing on two different occasions (3 days apart; $\mathrm{n}=10$ ) revealed a good test-retest reliability based on the intraclass correlation coefficient (ranging from 0.93 to 0.98 ) and technical error measurement (ranging from 2.8 to $4.8 \%$ ) results.

When performing the $45^{\circ}$-one-legged squat, all participants began in an upright position with both knees stretched $\left(180^{\circ}\right)$ and both hands on the waist with an elbow angle of approximately $90^{\circ}$. The participant was instructed to bend the knee of the leg he/she was standing on to $45^{\circ}$ and avoid ground contact with the other foot. (A larger knee angle was not possible, since our untrained participants were not strong or stable enough). After bending, the participant returned to the upright position with both knees stretched $\left(180^{\circ}\right)$, thereby ending the cycle. This testing started with the right leg; after a 30-s break, the left leg was tested in the same manner and the average number of repetitions with both legs used for statistical analysis.

The push-ups at $\mathrm{T}_{0}, \mathrm{~T}_{1}$ and $\mathrm{T}_{2}$ were performed in the same manner. When the participant was unable to raise his/her elongated torso and lower-body from the floor, he/she was allowed to perform subsequent push-ups while kneeling. One push-up began when the torso was lifted from the floor and ended when it touched the floor again.

During the leg lever test the participant lay stretched out on a fitness mat with both arms and hands held close in to the body. The cycle began with both legs, knees fully extended, being raised simultaneously to an angle of $60^{\circ}$ at the hip. The cycle ended when both legs were lowered slightly without the heels touching the ground. Thereafter, this cycle was repeated, and the number of repetitions employed for statistical analysis.

A valid burpee began in the standing position, from which the participant moved into a squatting position with the two legs simultaneously kicking back, to land in a plank position on both hands and tiptoes. Then, the participant returned to the squat position and ended the burpee with a vertical jump. This cycle was repeated, and the number of repetitions employed for statistical analysis.

Skipping performance was assessed as the maximal number of skips during a 30-s period, as recorded by the OptoJump apparatus (MicroGate Srl, Bolzano, Italy).

\section{Assessment of Quality of Life}

At $\mathrm{T}_{0}, \mathrm{~T}_{1}$, and $\mathrm{T}_{2}$, all completed the German version of the health-related quality of life questionnaire (SF-36), which has been confirmed to be both valid and reliable (Bullinger et al., 1995). This questionnaire assesses general and mental health, physical and social functioning, vitality, bodily pain, and the impact of physical and emotional limitations, with higher scores $(0-100)$ reflecting better quality of life. The questionnaire was distributed to the participants by a member of our research group prior to physiological testing and later collected by the same person.

\section{Monitoring Activity and Training}

Collection of data on activity was initiated immediately after the first ramp test $\left(\mathrm{T}_{0}\right)$ and terminated after the last ramp test approximately 8 weeks later $\left(\mathrm{T}_{2}\right)$. Each individual wore a multisensory device (Polar V800, Polar Electro Oy, Kempele, Finland) on the wrist on which they usually wore a watch for the entire study period (with the exception of short intervals for charging). When the participants were not exercising, the Polar V800 instrument without a chest-belt recorded the number of steps and intensity of daily activities automatically, with a validity comparable to that of accelerometers (Hernandez-Vicente et al., 2016). During each session of Circuit $t_{\text {HIT }}$ they wore a chest-belt and activated monitoring of heart rate manually. Each participant uploaded all these data for web-based storage via the Polar Flow software. This software provides the number of steps taken daily, the number of waking hours spent sedentary each day $[<1.5$ metabolic equivalents (MET)], and the time spent performing light (1.5-3 MET), moderate (3-6 MET) and vigorous physical activity ( $>6$ MET) each day. For the analysis of each Circuit ${ }_{\text {HIIT }}$ session, we averaged the heart rate data from the last $2 \mathrm{~min}$.

\section{Statistical Analyses}

When the distribution of the data was examined with the Shapiro-Wilk test, this distribution was found to be non-normal in the case of physical activity and health-related quality of life (SF-36). Since further data transformation did not improve this situation, we continued with parametric testing. Repeated measures ANOVAs (time points: baseline and intervention for physical activity and $T_{0}, T_{1}, T_{2}$ for all other variables) were performed with the physical activity, cardiorespiratory and metabolic parameters, body composition, functional strength and quality of life as the intra-subject factors and group (1xCircuit HIIT $_{\text {or }} 2 \mathrm{xCircuit}_{\mathrm{HIIT}}$ ) as the inter-subject factor. An alpha of $\rho<0.05$ with Bonferroni adjustment for multiple comparisons was considered significant. In addition, the values obtained were evaluated by calculating the effect size partial etasquare $\left(\eta_{p}{ }^{2}\right)$. The means and standard deviations (SD) of all data sets were calculated and all statistical tests carried out in the SPSS 22.0 software package for Microsoft (SPSS Inc., Chicago, IL, United States).

\section{RESULTS}

\section{Activity Measurements (Table 2)}

For the 1 Circuit $_{\text {HIIT }}$ group, valid data (i.e., $>480 \mathrm{~min} /$ day) were obtained for $19.2 \pm 1.5$ weekdays and $7.4 \pm 1.2$ weekend days during the 4-week baseline period and $18.8 \pm 1.8$ weekdays and $6.9 \pm 1.4$ weekend days during the 4 -week intervention. The corresponding values for the $2 \mathrm{xCircuit}_{\mathrm{HIT}}$ group were $18.5 \pm 2.9$ and $7.6 \pm 1.2$ vs. $18.9 \pm 1.9$ and $7.4 \pm 1.3$ days, respectively. The mean sedentary time and duration of light, moderate and vigorous physical activity are presented in Table 2. 
TABLE 2 | Activity parameters (means \pm SD) for the 1xCircuit HIIT $_{\text {and } 2 \times \text { Circuit }}$ HII groups during the baseline (first 4-week) and intervention (second 4-week) periods.

\begin{tabular}{|c|c|c|c|c|c|c|c|}
\hline Parameter & Days & $\begin{array}{c}\text { Circuit }_{\text {HIIT }} \\
\text { group }\end{array}$ & Baseline & Intervention & $\begin{array}{c}p(T) / p(G) / \\
p(T \times G)\end{array}$ & $\begin{array}{c}\eta_{p}^{2}(T) / \eta_{p}^{2}(G) / \eta_{p}^{2} \\
(T \times G)\end{array}$ & $\begin{array}{c}F(T) / F(G) / \\
F(T \times G)\end{array}$ \\
\hline Days for which valid & Weekdays & $1 x$ & $19.2 \pm 1.5$ & $18.8 \pm 1.8$ & 0.962 & 0.000 & 0.002 \\
\hline \multirow[t]{5}{*}{ data were obtained $[n]$} & & $2 x$ & $18.5 \pm 2.9$ & $18.9 \pm 1.9$ & 0.727 & 0.006 & 0.125 \\
\hline & & & & & 0.491 & 0.023 & 0.491 \\
\hline & Saturday-Sunday & $1 x$ & $7.4 \pm 1.2$ & $6.9 \pm 1.4$ & 0.275 & 0.057 & 1.259 \\
\hline & & $2 x$ & $7.6 \pm 1.2$ & $7.4 \pm 1.3$ & 0.424 & 0.031 & 0.664 \\
\hline & & & & & 0.745 & 0.005 & 0.109 \\
\hline Total time during which & Weekdays & $1 x$ & $20.8 \pm 3.8$ & $20.1 \pm 4.0$ & 0.466 & 0.026 & 0.551 \\
\hline \multirow[t]{5}{*}{ the sensor was worn [h] } & & $2 x$ & $21.1 \pm 4.7$ & $20.9 \pm 3.5$ & 0.731 & 0.006 & 0.121 \\
\hline & & & & & 0.691 & 0.008 & 0.163 \\
\hline & Saturday-Sunday & $1 x$ & $19.3 \pm 5.2$ & $19.6 \pm 4.7$ & 0.689 & 0.008 & 0.165 \\
\hline & & $2 x$ & $21.4 \pm 4.1$ & $20.4 \pm 5.2$ & 0.440 & 0.029 & 0.620 \\
\hline & & & & & 0.486 & 0.023 & 0.504 \\
\hline \multirow[t]{6}{*}{ Steps $[n]$} & Weekdays & $1 \mathrm{x}$ & $9788 \pm 2773$ & $9183 \pm 2339$ & 0.790 & 0.004 & 0.073 \\
\hline & & $2 x$ & $10142 \pm 4496$ & $10527 \pm 3965$ & 0.553 & 0.018 & 0.365 \\
\hline & & & & & 0.240 & 0.068 & 1.465 \\
\hline & Saturday-Sunday & $1 x$ & $8958 \pm 2507$ & $9020 \pm 2469$ & 0.738 & 0.006 & 0.115 \\
\hline & & $2 x$ & $8795 \pm 4972$ & $9177 \pm 4972$ & 0.999 & 0.000 & 0.000 \\
\hline & & & & & 0.809 & 0.003 & 0.069 \\
\hline Sedentary time (<1.5 MET) & Weekdays & $1 x$ & $9.3 \pm 1.9$ & $9.3 \pm 2.4$ & 0.616 & 0.014 & 0.260 \\
\hline \multirow[t]{5}{*}{ during waking hours [h] } & & $2 x$ & $8.9 \pm 2.1$ & $9.2 \pm 1.7$ & 0.755 & 0.005 & 0.100 \\
\hline & & & & & 0.651 & 0.011 & 0.212 \\
\hline & Saturday-Sunday & $1 x$ & $8.6 \pm 2.7$ & $8.0 \pm 2.8$ & 0.141 & 0.111 & 2.361 \\
\hline & & $2 x$ & $9.0 \pm 1.7$ & $8.0 \pm 2.8$ & 0.835 & 0.002 & 0.045 \\
\hline & & & & & 0.788 & 0.004 & 0.075 \\
\hline Light physical activity & Weekdays & $1 x$ & $4.1 \pm 1.0$ & $3.9 \pm 1.1$ & 0.341 & 0.043 & 0.948 \\
\hline \multirow[t]{5}{*}{ (1.5-3 MET) [h] } & & $2 x$ & $4.7 \pm 1.8$ & $4.3 \pm 1.8$ & 0.351 & 0.042 & 0.911 \\
\hline & & & & & 0.610 & 0.013 & 0.268 \\
\hline & Saturday-Sunday & $1 x$ & $4.0 \pm 0.9$ & $4.2 \pm 1.3$ & 0.676 & 0.009 & 0.180 \\
\hline & & $2 x$ & $4.6 \pm 2.1$ & $4.0 \pm 2.1$ & 0.747 & 0.005 & 0.107 \\
\hline & & & & & 0.341 & 0.043 & 0.948 \\
\hline Moderate physical activity & Weekdays & $1 x$ & $0.7 \pm 0.2$ & $0.6 \pm 0.2$ & 0.415 & 0.032 & 0.690 \\
\hline \multirow[t]{5}{*}{ (3-6 MET) [h] } & & $2 x$ & $0.8 \pm 0.3$ & $0.7 \pm 0.3$ & 0.494 & 0.023 & 0.485 \\
\hline & & & & & 0.913 & 0.001 & 0.012 \\
\hline & Saturday-Sunday & $1 \mathrm{x}$ & $0.6 \pm 0.2$ & $0.5 \pm 0.2$ & 0.340 & 0.046 & 0.957 \\
\hline & & $2 x$ & $0.6 \pm 0.4$ & $0.6 \pm 0.3$ & 0.717 & 0.007 & 0.135 \\
\hline & & & & & 0.340 & 0.046 & 0.957 \\
\hline Vigorous physical activity & Weekdays & $1 \mathrm{x}$ & $0.2 \pm 0.1$ & $0.2 \pm 0.1$ & 0.024 & 0.219 & 5.880 \\
\hline \multirow[t]{5}{*}{$(>6 \mathrm{MET})[\mathrm{h}]$} & & $2 x$ & $0.2 \pm 0.1$ & $0.3 \pm 0.2$ & 0.621 & 0.012 & 0.253 \\
\hline & & & & & 0.211 & 0.073 & 1.664 \\
\hline & Saturday-Sunday & $1 x$ & $0.1 \pm 0.1$ & $0.2 \pm 0.2$ & 0.029 & 0.206 & 5.456 \\
\hline & & $2 x$ & $0.1 \pm 0.1$ & $0.2 \pm 0.3$ & 0.800 & 0.003 & 0.066 \\
\hline & & & & & 0.395 & 0.035 & 0.753 \\
\hline
\end{tabular}

p, probability; $\eta_{p}^{2}$, effect size partial eta-square; MET, metabolic equivalent; T, global effect of time; G, global effect of Group; T $\times$ G, global effect of Time $\times$ Group.

The only difference between the intervention and baseline periods was that both groups performed more vigorous activity on all days of the week during the intervention.

\section{Training Adherence and Heart Rate}

During the intervention, participants in the 1 xCircuit $_{\text {HIT }}$ and 2 xCircuit $_{\mathrm{HIT}}$ groups performed 90.7 and $85.7 \%$, respectively, of all the planned training sessions, achieving
74.3 and $70.8 \%$ of maximal heart rate during these micro-sessions.

\section{Pre-Post Testing}

All of the parameters measured at $T_{0}, T_{1}$, and $T_{2}$ with accompanying statistical analyses are presented in Tables 2-5. Body, fat and fat-free mass and metabolic rate at rest were the same for both groups and at all of these time-points (Table 3). 


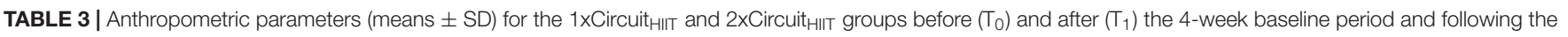
4-week intervention $\left(\mathrm{T}_{2}\right)$.

\begin{tabular}{|c|c|c|c|c|c|c|c|}
\hline Parameter & $\underset{\text { group }_{\text {grcuit }}}{\text { grou }}$ & $\mathrm{T}_{0}$ & $T_{1}$ & $\mathbf{T}_{2}$ & $\begin{array}{c}p(\mathrm{~T}) / p(\mathrm{G}) / \\
p(\mathrm{~T} \times \mathrm{G})\end{array}$ & $\begin{array}{c}\eta_{p}^{2}(T) / \eta_{p}^{2}(G) / \eta_{p}^{2} \\
(T \times G)\end{array}$ & $\begin{array}{c}F(T) / F(G) / \\
F(T \times G)\end{array}$ \\
\hline \multirow[t]{3}{*}{ Body mass [kg] } & $1 x$ & $73.1 \pm 10.6$ & $73.2 \pm 10.7$ & $73.6 \pm 11.1$ & 0.462 & 0.071 & 0.801 \\
\hline & $2 x$ & $71.2 \pm 15.2$ & $71.5 \pm 15.2$ & $71.4 \pm 15.1$ & 0.720 & 0.006 & 0.132 \\
\hline & & & & & 0.317 & 0.104 & 1.213 \\
\hline \multirow[t]{3}{*}{ Fat-free mass [\%] } & $1 x$ & $33.3 \pm 4.7$ & $32.9 \pm 4.5$ & $33.2 \pm 5.2$ & 0.119 & 0.184 & 2.361 \\
\hline & $2 x$ & $34.6 \pm 5.6$ & $34.0 \pm 6.0$ & $34.6 \pm 5.9$ & 0.560 & 0.016 & 0.351 \\
\hline & & & & & 0.868 & 0.013 & 0.143 \\
\hline \multirow[t]{3}{*}{ Fat mass [kg] } & $1 x$ & $26.5 \pm 7.0$ & $27.2 \pm 6.7$ & $27.1 \pm 7.2$ & 0.138 & 0.172 & 2.182 \\
\hline & $2 x$ & $24.8 \pm 8.2$ & $25.7 \pm 8.9$ & $24.8 \pm 8.9$ & 0.565 & 0.015 & 0.341 \\
\hline & & & & & 0.725 & 0.030 & 0.327 \\
\hline \multirow[t]{3}{*}{ Metabolic rate at rest [kcal] } & $1 x$ & $1551 \pm 208$ & $1548 \pm 211$ & $1555 \pm 242$ & 0.815 & 0.019 & 0.207 \\
\hline & $2 x$ & $1555 \pm 269$ & $1557 \pm 268$ & $1560 \pm 265$ & 0.952 & 0.000 & 0.004 \\
\hline & & & & & 0.629 & 0.043 & 0.473 \\
\hline
\end{tabular}

p, probability; $\eta_{p}^{2}$, effect size partial eta-square; T, global effect of time; G, global effect of Group; $T \times$ G, global effect of Time $\times$ Group.

TABLE 4 | Cardio-respiratory and metabolic parameters (means \pm SD) for the $1 \times$ Circuit $_{H I T}$ and $2 \times$ Circuit HIT $_{\text {groups before }}\left(T_{0}\right)$ and after $\left(T_{1}\right)$ the 4 -week baseline period and following the 4-week intervention $\left(T_{2}\right)$.

\begin{tabular}{|c|c|c|c|c|c|c|c|}
\hline Parameter & $\begin{array}{c}\text { Circuit }_{\text {HIIT }} \\
\text { group }\end{array}$ & $\mathbf{T}_{0}$ & $\mathbf{T}_{1}$ & $\mathbf{T}_{2}$ & $\begin{array}{c}p(\mathrm{~T}) / p(\mathrm{G}) / \\
p(\mathrm{~T} \times \mathrm{G})\end{array}$ & $\begin{array}{c}\eta_{p}^{2}(T) / \eta_{p}^{2}(G) / \eta_{p}^{2} \\
(T \times G)\end{array}$ & $\begin{array}{c}F(T) / F(G) / \\
F(T \times G)\end{array}$ \\
\hline \multicolumn{8}{|l|}{ At submaximal running speed } \\
\hline \multirow[t]{3}{*}{ Heart rate $[\mathrm{bpm}]$} & $1 \mathrm{x}$ & $139 \pm 13$ & $134 \pm 17$ & $133 \pm 15$ & $0.017^{a, b}$ & 0.336 & 5.054 \\
\hline & $2 x$ & $136 \pm 12$ & $129 \pm 12$ & $129 \pm 14$ & 0.412 & 0.032 & 0.700 \\
\hline & & & & & 0.871 & 0.014 & 0.139 \\
\hline \multirow[t]{3}{*}{ Oxygen uptake $\left[\mathrm{ml} \cdot \mathrm{min}^{-1} \mathrm{~kg}^{-1}\right]$} & $1 \mathrm{x}$ & $17.7 \pm 1.3$ & $17.2 \pm 1.4$ & $17.3 \pm 1.3$ & 0.458 & 0.072 & 0.811 \\
\hline & $2 x$ & $17.6 \pm 2.5$ & $17.1 \pm 1.5$ & $17.1 \pm .8$ & 0.869 & 0.001 & 0.028 \\
\hline & & & & & 0.952 & 0.005 & 0.049 \\
\hline \multirow[t]{3}{*}{ Respiratory exchange ratio } & $1 x$ & $0.81 \pm .02$ & $0.82 \pm .03$ & $0.81 \pm .04$ & 0.495 & 0.065 & 0.728 \\
\hline & $2 x$ & $0.81 \pm .05$ & $0.82 \pm .04$ & $0.81 \pm .04$ & 0.742 & 0.005 & 0.111 \\
\hline & & & & & 0.889 & 0.011 & 0.118 \\
\hline \multicolumn{8}{|l|}{ At the point of exhaustion } \\
\hline \multirow[t]{3}{*}{ Maximal heart rate [bpm] } & $1 x$ & $192 \pm 8$ & $191 \pm 8$ & $191 \pm 8$ & 0.791 & 0.022 & 0.237 \\
\hline & $2 x$ & $189 \pm 10$ & $188 \pm 9$ & $188 \pm 9$ & 0.365 & 0.037 & 0.856 \\
\hline & & & & & 0.951 & 0.005 & 0.050 \\
\hline \multirow[t]{3}{*}{ Maximal oxygen uptake $\left[\mathrm{ml} \cdot \mathrm{min}^{-1}\right]$} & $1 x$ & $40.9 \pm 5.5$ & $41.2 \pm 6.5$ & $40.7 \pm 6.9$ & 0.286 & 0.112 & 1.328 \\
\hline & $2 x$ & $40.1 \pm 7.0$ & $41.3 \pm 7.3$ & $41.7 \pm 6.3$ & 0.977 & 0.000 & 0.001 \\
\hline & & & & & 0.476 & 0.068 & 0.770 \\
\hline \multicolumn{8}{|l|}{ After the point of exhaustion } \\
\hline \multirow[t]{3}{*}{ Heart rate recovery [bpm] } & $1 x$ & $28.8 \pm 12.1$ & $31.1 \pm 12.2$ & $32.7 \pm 10.7$ & 0.119 & 0.192 & 2.373 \\
\hline & $2 x$ & $28.6 \pm 8.9$ & $33.3 \pm 8.9$ & $26.9 \pm 7.6$ & 0.742 & 0.005 & 0.111 \\
\hline & & & & & 0.143 & 0.177 & 2.143 \\
\hline
\end{tabular}

$p$, probability; $\eta_{p}^{2}$, effect size partial eta-square; $T$, global effect of time; $G$, global effect of Group; $T \times G$, global effect of Time $\times$ Group; $a, T_{0}$ vs. $T_{1}$ ( $\left.p<0.05\right) ; b$, $T_{0}$ vs. $T_{2}(p<0.05)$.

Heart rate while running at $6 \mathrm{~km} / \mathrm{h}$ declined with time $(p=0.017)$ in both groups. All other variables (i.e., submaximal oxygen uptake and the respiratory exchange ratio, as well as peak oxygen uptake and maximal heart rate) were unaltered (Table 4).

The maximal numbers of push-ups, leg-levers, burpees, $45^{\circ}$ one-legged squats and 30-s skipping was greater at $T_{2}$ than $T_{1}$ for the participants in both groups, with no differences between $1 \mathrm{xCircuit}{ }_{\text {HIIT }}$ and 2xCircuit HIIT $_{\text {(Table 5). }}$.
Perception of general health improved following both interventions (Table 6).

\section{DISCUSSION}

Our major novel findings here concerning the psychophysiological responses of young untrained individuals to 4 weeks of either $1 \times$ Circuit HIIT or $2 x_{\text {CircuithilT were as }}$ 


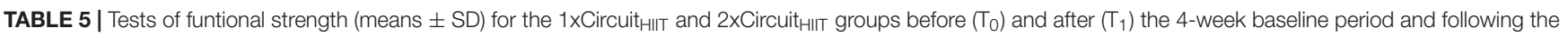
4-week intervention $\left(\mathrm{T}_{2}\right)$.

\begin{tabular}{|c|c|c|c|c|c|c|c|}
\hline Test $[n]$ & $\begin{array}{c}\text { Circuit }_{\text {HIIT }} \\
\text { group }\end{array}$ & $\mathrm{T}_{0}$ & $\mathbf{T}_{1}$ & $\mathbf{T}_{2}$ & $\begin{array}{c}p(\mathrm{~T}) / p(\mathrm{G}) / \\
p(\mathrm{~T} \times \mathrm{G})\end{array}$ & $\begin{array}{c}\eta_{p}^{2}(T) / \eta_{p}^{2}(G) / \\
\eta_{p}^{2}(T \times G)\end{array}$ & $\begin{array}{c}F(T) / F(G) / \\
F(T \times G)\end{array}$ \\
\hline \multirow[t]{3}{*}{ Push-ups } & $1 x$ & $28.9 \pm 13.4$ & $32.9 \pm 12.9$ & $35.6 \pm 8.5$ & $0.001^{b, c}$ & 0.520 & 10.838 \\
\hline & $2 x$ & $27.8 \pm 9.9$ & $28.6 \pm 9.0$ & $36.3 \pm 13.1$ & 0.719 & 0.006 & 0.133 \\
\hline & & & & & 0.109 & 0.199 & 2.486 \\
\hline \multirow[t]{3}{*}{ Leg-levers } & $1 x$ & $24.3 \pm 7.2$ & $24.3 \pm 6.5$ & $26.2 \pm 7.3$ & $0.001^{b, c}$ & 0.514 & 11.093 \\
\hline & $2 x$ & $22.7 \pm 5.3$ & $23.1 \pm 5.9$ & $27.4 \pm 6.4$ & 0.827 & 0.002 & 0.049 \\
\hline & & & & & 0.173 & 0.154 & 1.909 \\
\hline \multirow[t]{3}{*}{ Burpees } & $1 x$ & $16.9 \pm 3.2$ & $16.5 \pm 2.8$ & $19.3 \pm 3.0$ & $<0.001^{\mathrm{b}, \mathrm{c}}$ & 0.572 & 13.365 \\
\hline & $2 x$ & $16.4 \pm 4.7$ & $17.4 \pm 4.4$ & $20.7 \pm 6.4$ & 0.719 & 0.006 & 0.133 \\
\hline & & & & & 0.059 & 0.246 & 3.266 \\
\hline \multirow[t]{3}{*}{$45^{\circ}$-one-legged squats } & $1 x$ & $28.7 \pm 9.7$ & $35.3 \pm 11.1$ & $42.7 \pm 14.4$ & $<0.001^{a, b, c}$ & 0.699 & 24.389 \\
\hline & $2 x$ & $30.8 \pm 10.9$ & $36.6 \pm 13.7$ & $42.5 \pm 12.9$ & 0.818 & 0.002 & 0.054 \\
\hline & & & & & 0.832 & 0.017 & 0.186 \\
\hline \multirow[t]{3}{*}{ 30-s Skipping } & $1 x$ & $104.8 \pm 22.6$ & $101.8 \pm 17.1$ & $115.4 \pm 31.7$ & $0.015^{\mathrm{b}, \mathrm{c}}$ & 0.332 & 5.211 \\
\hline & $2 x$ & $87.6 \pm 23.9$ & $92.4 \pm 18.5$ & $106.5 \pm 25.3$ & 0.158 & 0.089 & 2.138 \\
\hline & & & & & 0.600 & 0.047 & 0.523 \\
\hline
\end{tabular}

p, probability; $\eta_{p}^{2}$, effect size partial eta-square; T, global effect of time; G, global effect of Group; $T \times$ G, global effect of Time $\times$ Group; a, $T_{0}$ vs. $T_{1}$ ( $\left.p<0.05\right) ; b$, To vs. $T_{2}(p<0.05) ; c, T_{1}$ vs. $T_{2}(p<0.05)$.

TABLE 6 | Quality of life (SF36; arbitrary units, means \pm SD) for the 1xCircuit HIT $_{\text {and } 2 \times C \text { ircuit }}$ IIT groups before ( $\left.T_{0}\right)$ and after $\left(T_{1}\right)$ the 4-week baseline period and following the 4-week intervention $\left(T_{2}\right)$.

\begin{tabular}{|c|c|c|c|c|c|c|c|}
\hline Item & $\begin{array}{c}\text { Circuit }_{\text {HIIT }} \\
\text { group }\end{array}$ & $\mathbf{T}_{0}$ & $\mathbf{T}_{1}$ & $\mathbf{T}_{2}$ & $\begin{array}{c}p(\mathrm{~T}) / p(\mathrm{G}) / \\
p(\mathrm{~T} \times \mathrm{G})\end{array}$ & $\begin{array}{c}\eta_{p}^{2}(T) / \eta_{p}^{2}(G) / \\
\eta_{p}^{2}(T \times G)\end{array}$ & $\begin{array}{c}F(T) / F(G) / \\
F(T \times G)\end{array}$ \\
\hline \multirow[t]{3}{*}{ Physical functioning } & $1 x$ & $95.5 \pm 7.6$ & $94.5 \pm 9.1$ & $94.5 \pm 8.8$ & 0.964 & 0.004 & 0.037 \\
\hline & $2 x$ & $98.6 \pm 2.3$ & $98.6 \pm 2.3$ & $99.1 \pm 3.0$ & 0.038 & 0.197 & 4.913 \\
\hline & & & & & 0.945 & 0.006 & 0.057 \\
\hline \multirow[t]{3}{*}{ Impact of physical limitations } & $1 x$ & $88.6 \pm 20.5$ & $79.5 \pm 40.0$ & $72.7 \pm 37.8$ & 0.403 & 0.091 & 0.954 \\
\hline & $2 x$ & $95.5 \pm 10.1$ & $81.8 \pm 33.7$ & $97.7 \pm 7.5$ & 0.153 & 0.100 & 2.210 \\
\hline & & & & & 0.323 & 0.112 & 1.199 \\
\hline \multirow[t]{3}{*}{ Pain } & $1 x$ & $84.9 \pm 19.1$ & $77.4 \pm 22.6$ & $76.9 \pm 19.4$ & 0.658 & 0.043 & 0.428 \\
\hline & $2 x$ & $87.5 \pm 16.0$ & $87.8 \pm 11.6$ & $88.2 \pm 16.8$ & 0.188 & 0.085 & 1.856 \\
\hline & & & & & 0.598 & 0.053 & 0.528 \\
\hline \multirow[t]{3}{*}{ Perception of general health } & $1 x$ & $74.8 \pm 16.6$ & $75.0 \pm 12.7$ & $78.3 \pm 12.1$ & $0.043^{\mathrm{a}}$ & 0.282 & 3.735 \\
\hline & $2 x$ & $76.8 \pm 14.0$ & $81.3 \pm 14.6$ & $83.3 \pm 13.7$ & 0.434 & 0.031 & 0.636 \\
\hline & & & & & 0.622 & 0.049 & 0.487 \\
\hline \multirow[t]{3}{*}{ Vitality } & $1 x$ & $60.5 \pm 11.3$ & $58.2 \pm 15.2$ & $57.7 \pm 13.8$ & 0.206 & 0.153 & 1.717 \\
\hline & $2 x$ & $60.9 \pm 9.4$ & $53.2 \pm 18.2$ & $55.9 \pm 19.5$ & 0.676 & 0.009 & 0.180 \\
\hline & & & & & 0.668 & 0.042 & 0.412 \\
\hline \multirow[t]{3}{*}{ Social functioning } & $1 x$ & $89.8 \pm 15.6$ & $89.8 \pm 16.6$ & $95.5 \pm 10.1$ & 0.722 & 0.034 & 0.331 \\
\hline & $2 x$ & $86.4 \pm 22.7$ & $81.8 \pm 22.6$ & $84.1 \pm 23.1$ & 0.196 & 0.082 & 1.786 \\
\hline & & & & & 0.767 & 0.028 & 0.269 \\
\hline \multirow[t]{3}{*}{ Impact of emotional limitations } & $1 x$ & $90.9 \pm 21.6$ & $87.9 \pm 27.0$ & $90.9 \pm 15.6$ & 0.832 & 0.019 & 0.186 \\
\hline & $2 x$ & $75.8 \pm 33.6$ & $69.7 \pm 45.8$ & $69.7 \pm 40.7$ & 0.162 & 0.113 & 2.547 \\
\hline & & & & & 0.893 & 0.012 & 0.114 \\
\hline \multirow[t]{3}{*}{ Mental health } & $1 x$ & $78.2 \pm 8.1$ & $78.9 \pm 10.7$ & $80.4 \pm 9.5$ & 0.613 & 0.050 & 0.501 \\
\hline & $2 x$ & $78.9 \pm 10.6$ & $73.7 \pm 15.2$ & $73.8 \pm 14.1$ & 0.391 & 0.037 & 0.770 \\
\hline & & & & & 0.191 & 0.160 & 1.810 \\
\hline
\end{tabular}

p, probability; $\eta_{p}^{2}$, effect size partial eta-square; T, global effect of time; G, global effect of Group; $T \times$ G, global effect of Time $\times$ Group; a, $T_{0}$ vs. $T_{2}$ ( $p<0.05$ ).

follows: (1) Neither intervention influenced the number of steps taken daily or amount of sedentary time or light or moderate physical activity, but the amount of vigorous physical activity by both groups was higher during the intervention than baseline period. (2) Body composition remained unchanged. (3) With the exception of heart rate while running at $6 \mathrm{~km} / \mathrm{h}$, 
no cardiorespiratory or metabolic parameters differed between the time-points of measurements or between the groups. (4) All parameters related to functional strength were improved following both interventions. And, finally, (5) perception of general health was also better after both $1 x_{\text {Circuit }}$ HIIT and 2 Xircuit $_{\text {HITT. }}$.

In the current investigation adherence to the prescribed exercise program was quite high ( $>85 \%$ of all planned sessions), despite the fact that there was no social networking by our participants nor did we provide reminders via social media, a calendar for scheduling or encouragement when lapses occurred - all effective strategies in connection with mobile apps designed for weight loss (Pagoto et al., 2013). This high degree of adherence may reflect the fact that the intervention was relatively short, scientific, and detailed, as well as the fact that the individual sessions did not take much time. In this regards it was not unexpected that there was no change in the sedentary time or amounts of light and moderate physical activity.

Overall, the changes in functional strength were more pronounced than those in cardiorespiratory parameters. Although there is now a generally accepted definition of functional strength, we describe the training program employed here more specifically as multi-joint exercise designed to improve certain dimensions of strength and mobility in connection with everyday life, as well as the performance of specific sports. Depending on its intensity, duration and frequency, this type of strength training promotes the same changes in neuro-muscular structure and function as traditional strength training - i.e., release of inhibitory mechanisms, as well as improvements in intra- and intermuscular coordination (synchronization, recruitment and the rate coding of muscle fibers) and hypertrophic responses.

Although the hypertrophic response to eccentric and concentric signaling occurs immediately (Franchi et al., 2017), the gains in muscle protein mass may take several weeks (Moritani and deVries, 1979) or months (Zinner et al., 2017), depending on factors that include both training history and gender. Therefore, the improvement in functional strength caused by the present 4-week intervention (7.8-20.9 and 15.2-26.9\% improvement with $1 \mathrm{xCircuit}_{\mathrm{HIT}}$ and $2 \mathrm{xCircuit}_{\mathrm{HIT}}$, respectively) probably reflects neural adaptation. Indeed, functional resistance training improves, e.g., health-related quality of life and physical fitness in women with chronic lowback pain (Cortell-Tormo et al., 2018) and it would be desirable to investigate the potential beneficial effects of our Circuit ${ }_{\text {HIT }}$ in this context.

Interestingly, even though one group trained twice as much as the other, the parameters examined differed between them to only a small extent. Accordingly, from a practical point of view, a single 6-min daily session of functional Circuit ${ }_{\text {HIIT }}$ as described here appears to improve functional strength by $7.8-$ $20.9 \%$.

In contrast to these gains in functional strength, no cardiorespiratory changes were evoked here by either 1 xCircuit ${ }_{\text {HIIT }}$ or 2 xCircuit $_{\text {HIIT. Peak oxygen uptake, which }}$ limits ATP production via oxidative phosphorylation, is regarded as an integrative indicator of CRF and is closely associated with general health and premature death (Bassett and Howley, 2000; Bouchard et al., 2015). There may be several reasons why this important variable was unaltered by our interventions: First, these Circuit $_{\text {HIIT }}$ interventions consisted primarily of resistance training (i.e., squats, lunges, push-ups, etc.). Second, meta-analyses recommend that in order to improve $\mathrm{VO}_{2}$ peak, a program of resistance circuit-based training should involve 14-30 sessions over a period of 6-12 weeks, with each session lasting at least $20-30 \mathrm{~min}$ at an exercise intensity of $60-90 \%$ of the one-repetition maximum (Munoz-Martinez et al., 2017). Thus, a recent intervention involving similar functional movements, but longer sessions (>60 min vs. $6 \mathrm{~min}$ ) over a longer period (9 vs. 4 weeks) than ours enhanced $\mathrm{VO}_{2}$ peak approximately $10 \%$ (Sperlich et al., 2017). Apparently, our intervention did not induce any central cardiovascular adaptations because both the individual sessions and overall length were too short and the overall intensities of 74.3 and $70.8 \%$ of peak heart rate during 1 xCircuit HIT $_{\text {and }} 2 \mathrm{xCircuit}_{\mathrm{HIT}}$, respectively, were not sufficiently high (i.e., approximately $90 \%$ of maximal heart rate).

This probably also explains the lack of any alteration in metabolism in response to our interventions. A reduction in the respiratory exchange ratio following a period of exercise is indicative of elevated lipid oxidation resulting from more extensive uptake of free fatty acids by working muscle, more efficient beta-oxidation, and down-regulation of glycolytic pathways (Dudley et al., 1987; Jansson and Kaijser, 1987; Brooks, 1997; Bergman and Brooks, 1999). Although endurance exercise increases fatty acid oxidation to a greater extent (Goodpaster et al., 2003; Berggren et al., 2004), even exercise of low-tomoderate intensity [i.e., ranging from 33 to $65 \% \mathrm{VO}_{2 \max }$ (Achten et al., 2002)] also has such a beneficial effect (Jones et al., 1980; Broeder et al., 1991; Romijn et al., 1993; Bergman and Brooks, 1999). The heart rates during our Circuit ${ }_{\text {HIT }}$ indicate that the mean intensity of this training (although not targeted) can be classified as "moderate." Nevertheless, no changes in lipid or carbohydrate metabolism occurred, perhaps, once again, because the individual sessions and overall length of our interventions were too short.

Interestingly, 30-s skipping, which involves anaerobic metabolism (Quirk and Sinning, 1982), improved in both groups by $13.8-15.8 \%$. Since rapid knee lifting is related to leg strength and neuro-muscular control (Trecroci et al., 2015), this improvement may reflect the gains in functional leg strength discussed above.

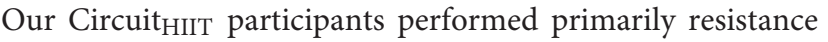
training (i.e., squats, lunges, push-ups, etc.) with very little rest. Therefore, it is not surprising that their functional strength increased. However, the magnitude of this increase (as much as $48 \%$ for certain parameters) with only 6-min micro-sessions of Circuit $_{\text {HIIT }}$ daily is remarkable.

Women who performed approximately 60 min of Circuit ${ }_{H I T}$ each week experienced more pain after the 9-week intervention (Sperlich et al., 2017). Indeed, high-intensity strength training with eccentric components such as those involved in multistimulating, circuit-like, multiple-joint training induces muscle soreness. Although we did not assess pain during each training session, our participants perceived no more pain after the 
$1 \mathrm{x}$ and $2 \mathrm{xCircuit}_{\mathrm{HIIT}}$ than during the baseline period. Furthermore, although the rate of injury associated with multistimulating, circuit-like, multiple-joint training is approximately $20 \%$ (Weisenthal et al., 2014), none of our participants in either group mentioned any severe injury. Finally, our 1 xCircuit ${ }_{\mathrm{HIT}}$ and $2 \mathrm{x}$ Circuit $_{\mathrm{HIIT}}$ interventions both appeared to improve perception of general health.

From a methodological perspective, the web-based Circuit ${ }_{\text {HIIT }}$ employed here was not customized to account for individual strengths and weaknesses, which would be desirable in connection with future applications. In addition, although the participants were instructed to perform the Circuit ${ }_{H I I T}$ "all-out," their heart rates revealed that the intensity of exercise was actually relatively "moderate." We did not monitor ratings of perceived exertion after the CircuitHIIT, which should be done in future studies of this kind. In addition, we cannot be certain that the participants performed each exercise correctly, which is a general limitation of mobilebased exercise. Moreover, our home workouts were assessed by monitoring heart rate and we cannot entirely exclude the possibility that someone other than the participant him/herself was wearing the sensor. Furthermore, seasonal variation in free-living activity may explain in part the decline in submaximal heart rate from $\mathrm{T}_{0}$ to $\mathrm{T}_{1}$. In this study the groups were matched according to their $\mathrm{VO}_{2 \text { peak }}$ and not functional strength. Since the performances in functional strength were heterogenous among the participants (as evidence, e.g., by the standard deviation in Table 5) this might explain why

\section{REFERENCES}

Achten, J., Gleeson, M., and Jeukendrup, A. E. (2002). Determination of the exercise intensity that elicits maximal fat oxidation. Med. Sci. Sports Exerc. 34, 92-97. doi: 10.1097/00005768-200201000-00015

Atkinson, N. L., and Gold, R. S. (2002). The promise and challenge of eHealth interventions. Am. J. Health Behav. 26, 494-503. doi: 10.5993/AJHB.26.6.10

Barnes, K. R., and Kilding, A. E. (2015). Strategies to improve running economy. Sports Med. 45, 37-56. doi: 10.1007/s40279-014-0246-y

Bassett, D. R. Jr., and Howley, E. T. (2000). Limiting factors for maximum oxygen uptake and determinants of endurance performance. Med. Sci. Sports Exerc. 32, 70-84. doi: 10.1097/00005768-200001000-00012

Berggren, J. R., Hulver, M. W., Dohm, G. L., and Houmard, J. A. (2004). Weight loss and exercise: implications for muscle lipid metabolism and insulin action. Med. Sci. Sports Exerc. 36, 1191-1195. doi: 10.1249/01.MSS.0000074670. 03001.98

Bergman, B. C., and Brooks, G. A. (1999). Respiratory gas-exchange ratios during graded exercise in fed and fasted trained and untrained men. J. Appl. Physiol. 86, 479-487. doi: 10.1152/jappl.1999.86.2.479

Blair, S. N., Kohl, H. W. III, Paffenbarger, R. S. Jr., Clark, D. G., Cooper, K. H., and Gibbons, L. W. (1989). Physical fitness and all-cause mortality. A prospective study of healthy men and women. JAMA 262, 2395-2401. doi: 10.1001/jama. 1989.03430170057028

Bort-Roig, J., Gilson, N. D., Puig-Ribera, A., Contreras, R. S., and Trost, S. G. (2014). Measuring and influencing physical activity with smartphone technology: a systematic review. Sports Med. 44, 671-686. doi: 10.1007/s40279014-0142-5

Bouchard, C., Blair, S. N., and Katzmarzyk, P. T. (2015). ). Less sitting, more physical activity, or higher fitness. Mayo Clin. Proc. 90, 1533-1540. doi: 10.1016/ j.mayocp.2015.08.005

Broeder, C. E., Brenner, M., Hofman, Z., Paijmans, I. J. M., Thomas, E. L., and Wilmore, J. H. (1991). The metabolic consequences of low and moderate no differences were detectable between groups. The current investigation was designed to assess the responses of, in particular, untrained individuals to mobile CircuitHIIT and future evaluation of more long-term responses (e.g., > 10 weeks) is required.

\section{CONCLUSION}

Four weeks of either one or two 6-min micro-sessions of multistimulating, circuit-like, multiple-joint training daily improves certain parameters of functional strength and certain dimensions of quality of life in untrained individuals. However, such exercise programs do not enhance cardio-respiratory fitness, having no effect in particular on peak oxygen uptake.

\section{AUTHOR CONTRIBUTIONS}

All authors listed have made a substantial, direct and intellectual contribution to the work, and approved it for publication.

\section{FUNDING}

This publication was funded by the German Research Foundation (DFG) and the University of Wuerzburg in the funding program Open Access Publishing.

intensity exercise with or without feeding in lean and borderline obese males. Int. J. Obes. 15, 95-104.

Brooks, G. A. (1997). Importance of the 'crossover' concept in exercise metabolism. Clin. Exp. Pharmacol. Physiol. 24, 889-895. doi: 10.1111/j.1440-1681.1997. tb02712.x

Bullinger, M., Kirchberger, I., and Ware, J. (1995). Der deutsche SF-36 Health Survey Übersetzung und psychometrische Testung eines krankheitsübergreifenden Instruments zur Erfassung der gesundheitsbezogenen Lebensqualität. Z. Gesundh. Wiss. 3, 21-36. doi: 10.1007/ BF02959944

Cholewa, J. M., Rossi, F. E., Macdonald, C., Hewins, A., Gallo, S., Micenski, A., et al. (2017). The effects of moderate- versus high-load resistance training on muscle growth, body composition, and performance in collegiate women. J. Strength Cond. Res. doi: 10.1519/JSC.0000000000002048 [Epub ahead of print].

Cortell-Tormo, J. M., Sanchez, P. T., Chulvi-Medrano, I., Tortosa-Martinez, J., Manchado-Lopez, C., Llana-Belloch, S., et al. (2018). Effects of functional resistance training on fitness and quality of life in females with chronic nonspecific low-back pain. J. Back Musculoskelet. Rehabil. 31, 95-105. doi: 10.3233/BMR-169684

Daanen, H. A., Lamberts, R. P., Kallen, V. L., Jin, A., and Van Meeteren, N. L. (2012). A systematic review on heart-rate recovery to monitor changes in training status in athletes. Int. J. Sports Physiol. Perform. 7, 251-260. doi: 10.1123/ijspp.7.3.251

DeFina, L. F., Haskell, W. L., Willis, B. L., Barlow, C. E., Finley, C. E., Levine, B. D., et al. (2015). Physical activity versus cardiorespiratory fitness: two (partly) distinct components of cardiovascular health? Prog. Cardiovasc. Dis. 57, 324-329. doi: 10.1016/j.pcad.2014.09.008

Dudley, G. A., Tullson, P. C., and Terjung, R. L. (1987). Influence of mitochondrial content on the sensitivity of respiratory control. J. Biol. Chem. 262, 9109-9114.

Elliott, A. D., Rajopadhyaya, K., Bentley, D. J., Beltrame, J. F., and Aromataris, E. C. (2014). Interval training versus continuous exercise in patients with coronary 
artery disease: a meta-analysis. Heart Lung Circ. 24, 149-157. doi: 10.1016/j.hlc. 2014.09.001

Franchi, M. V., Reeves, N. D., and Narici, M. V. (2017). Skeletal muscle remodeling in response to eccentric vs. concentric loading: morphological, molecular, and metabolic adaptations. Front. Physiol. 8:447. doi: 10.3389/fphys.2017.00447

Garber, C. E., Blissmer, B., Deschenes, M. R., Franklin, B. A., Lamonte, M. J., Lee, I. M., et al. (2011). American college of sports medicine position stand. Quantity and quality of exercise for developing and maintaining cardiorespiratory, musculoskeletal, and neuromotor fitness in apparently healthy adults: guidance for prescribing exercise. Med. Sci. Sports Exerc. 43, 1334-1359. doi: 10.1249/ MSS.0b013e318213fefb

Gibala, M. J., Little, J. P., Macdonald, M. J., and Hawley, J. A. (2012). Physiological adaptations to low-volume, high-intensity interval training in health and disease. J. Physiol. 590, 1077-1084. doi: 10.1113/jphysiol.2011.224725

Gielen, S., Laughlin, M. H., O'conner, C., and Duncker, D. J. (2015). Exercise training in patients with heart disease: review of beneficial effects and clinical recommendations. Prog. Cardiovasc. Dis. 57, 347-355. doi: 10.1016/j.pcad.2014. 10.001

Godin, G., Desharnais, R., Valois, P., Lepage, L., Jobin, J., and Bradet, R. (1994). Differences in perceived barriers to exercise between high and low intenders: observations among different populations. Am. J. Health Promot. 8, 279-385. doi: 10.4278/0890-1171-8.4.279

Goodpaster, B. H., Katsiaras, A., and Kelley, D. E. (2003). Enhanced fat oxidation through physical activity is associated with improvements in insulin sensitivity in obesity. Diabetes Metab. Res. Rev. 52, 2191-2197. doi: 10.2337/diabetes.52.9. 2191

Hernandez-Vicente, A., Santos-Lozano, A., De Cocker, K., and Garatachea, N. (2016). Validation study of Polar V800 accelerometer. Ann. Transl. Med. 4:278. doi: 10.21037/atm.2016.07.16

Jansson, E., and Kaijser, L. (1987). Substrate utilization and enzymes in skeletal muscle of extremely endurance-trained men. J. Appl. Physiol. 62, 999-1005. doi: 10.1152/jappl.1987.62.3.999

Jones, N. L., Heigenhauser, G. J., Kuksis, A., Matsos, C. G., Sutton, J. R., and Toews, C. J. (1980). Fat metabolism in heavy exercise. Clin. Sci. 59, 469-478. doi: $10.1042 / \operatorname{cs} 0590469$

Kessler, H. S., Sisson, S. B., and Short, K. R. (2012). The potential for highintensity interval training to reduce cardiometabolic disease risk. Sports Med. 42, 489-509. doi: 10.2165/11630910-000000000-00000

Knight, E., Stuckey, M. I., Prapavessis, H., and Petrella, R. J. (2015). Public health guidelines for physical activity: is there an app for that? A review of android and apple app stores. JMIR Mhealth Uhealth 3:e43. doi: 10.2196/mhealth. 4003

Little, J. P., and Francois, M. E. (2014). High-intensity interval training for improving postprandial hyperglycemia. Res. Q. Exerc. Sport 85, 451-456. doi: 10.1080/02701367.2014.963474

Mayhew, T. P., Rothstein, J. M., Finucane, S. D., and Lamb, R. L. (1995). Muscular adaptation to concentric and eccentric exercise at equal power levels. Med. Sci. Sports Exerc. 27, 868-873. doi: 10.1249/00005768-19950600000011

Modave, F., Bian, J., Leavitt, T., Bromwell, J., Harris Iii, C., and Vincent, H. (2015). Low quality of free coaching apps with respect to the american college of sports medicine guidelines: a review of current mobile apps. JMIR Mhealth Uhealth 3:e77. doi: 10.2196/mhealth.4669

Moritani, T., and deVries, H. A. (1979). Neural factors versus hypertrophy in the time course of muscle strength gain. Am. J. Phys. Med. 58, $115-130$.

Munoz-Martinez, F. A., Rubio-Arias, J. A., Ramos-Campo, D. J., and Alcaraz, P. E. (2017). Effectiveness of resistance circuit-based training for maximum oxygen uptake and upper-body one-repetition maximum improvements: a systematic review and meta-analysis. Sports Med. 47, 2553-2568. doi: 10.1007/s40279-0170773-4

Nikander, R., Sievanen, H., Heinonen, A., Daly, R. M., Uusi-Rasi, K., and Kannus, P. (2010). Targeted exercise against osteoporosis: a systematic review and meta-analysis for optimising bone strength throughout life. BMC Med. 8:47. doi: 10.1186/1741-7015-8-47

Pagoto, S., Schneider, K., Jojic, M., Debiasse, M., and Mann, D. (2013). Evidencebased strategies in weight-loss mobile apps. Am. J. Prev. Med. 45, 576-582. doi: $10.1016 /$ j.amepre.2013.04.025
Petersen, B. A., Hastings, B., and Gottschall, J. S. (2017). Low load, high repetition resistance training program increases bone mineral density in untrained adults. J. Sports Med. Phys. Fitness 57, 70-76. doi: 10.23736/S0022-4707.16.05697-8

Poole, D. C., and Jones, A. M. (2017). Measurement of the maximum oxygen uptake Vo2max: Vo2peak is no longer acceptable. J. Appl. Physiol. 122, 997-1002. doi: 10.1152/japplphysiol.01063.2016

Quirk, J. E., and Sinning, W. E. (1982). Anaerobic and aerobic responses of males and females to rope skipping. Med. Sci. Sports Exerc. 14, 26-29. doi: 10.1249/ 00005768-198201000-00005

Raue, U., Terpstra, B., Williamson, D. L., Gallagher, P. M., and Trappe, S. W. (2005). Effects of short-term concentric vs. eccentric resistance training on single muscle fiber MHC distribution in humans. Int. J. Sports Med. 26, 339-343. doi: 10.1055/s-2004-821041

Romijn, J. A., Coyle, E. F., Sidossis, L. S., Gastaldelli, A., Horowitz, J. F., Endert, E., et al. (1993). Regulation of endogenous fat and carbohydrate metabolism in relation to exercise intensity and duration. Am. J. Physiol. 265, E380-E391. doi: 10.1152/ajpendo.1993.265.3.E380

Sama, P. R., Eapen, Z. J., Weinfurt, K. P., Shah, B. R., and Schulman, K. A. (2014). An evaluation of mobile health application tools. JMIR Mhealth Uhealth 2:e19. doi: $10.2196 /$ mhealth.3088

Schmitt, J., Lindner, N., Reuss-Borst, M., Holmberg, H. C., and Sperlich, B. (2016). A 3-week multimodal intervention involving high-intensity interval training in female cancer survivors: a randomized controlled trial. Physiol. Rep. 4:e12693. doi: 10.14814/phy2.12693

Sothern, M. S., Loftin, M., Suskind, R. M., Udall, J. N., and Blecker, U. (1999). The health benefits of physical activity in children and adolescents: implications for chronic disease prevention. Eur. J. Pediatr. 158, 271-274. doi: 10.1007/ s004310051070

Sperlich, B., Wallmann-Sperlich, B., Zinner, C., Von Stauffenberg, V., Losert, H., and Holmberg, H. C. (2017). Functional high-intensity circuit training improves body composition, peak oxygen uptake, strength, and alters certain dimensions of quality of life in overweight women. Front. Physiol. 8:172. doi: 10.3389/fphys.2017.00172

Thomas, R. J., Kenfield, S. A., and Jimenez, A. (2017). Exercise-induced biochemical changes and their potential influence on cancer: a scientific review. Br. J. Sports Med. 51, 640-644. doi: 10.1136/bjsports-2016-096343

Trecroci, A., Cavaggioni, L., Caccia, R., and Alberti, G. (2015). Jump rope training: balance and motor coordination in preadolescent soccer players. J. Sports Sci. Med. 14, 792-798.

Weisenthal, B. M., Beck, C. A., Maloney, M. D., Dehaven, K. E., and Giordano, B. D. (2014). Injury rate and patterns among CrossFit athletes. Orthop. J. Sports Med. 2:2325967114531177. doi: 10.1177/2325967114531177

Whyte, L. J., Gill, J. M., and Cathcart, A. J. (2010). Effect of 2 weeks of sprint interval training on health-related outcomes in sedentary overweight/obese men. Metabolism 59, 1421-1428. doi: 10.1016/j.metabol.2010.01.002

www.sportsandscience.de (2017a). Microbout 6 Min HIIT Week 1. Available at: https://www.youtube.com/watch?v=uCHxY69EYxk

www.sportsandscience.de (2017b). Microbout 6 Min HIIT Week 2. Available at: https://www.youtube.com/watch? $\mathrm{v}=\mathrm{A} 2 \mathrm{qWMb} 47 \mathrm{U} 10 \& \mathrm{t}=42 \mathrm{~s}$

www.sportsandscience.de (2017c). Microbout 6 Min HIIT Week 3. Available at: https://www.youtube.com/watch?v=piqQ93b3pcg\&t=2s

www.sportsandscience.de (2017d). Microbout 6 Min HIIT Week 4. Available at: https://www.youtube.com/watch?v=8f-fYo5uDvw

Zinner, C., Baessler, B., Weiss, K., Ruf, J., Michels, G., Holmberg, H. C., et al. (2017). Effect of resistance training with vibration and compression on the formation of muscle and bone. Muscle Nerve 56, 1137-1142. doi: 10.1002/mus.25560

Conflict of Interest Statement: The authors declare that the research was conducted in the absence of any commercial or financial relationships that could be construed as a potential conflict of interest.

Copyright (c) 2018 Sperlich, Hahn, Edel, Behr, Helmprobst, Leppich, WallmannSperlich and Holmberg. This is an open-access article distributed under the terms of the Creative Commons Attribution License (CC BY). The use, distribution or reproduction in other forums is permitted, provided the original author(s) and the copyright owner are credited and that the original publication in this journal is cited, in accordance with accepted academic practice. No use, distribution or reproduction is permitted which does not comply with these terms. 